\title{
A Produção de Materiais Autorais Digitais Educacionais Interdisciplinares por Licenciandos e a Relação com a Docência
}

\author{
Luciana de Lima ${ }^{1}$, Gabriela Teles ${ }^{1}$, Danielle Gonzaga da Silva ${ }^{1}$, Robson Carlos \\ Loureiro ${ }^{1}$ \\ ${ }^{1}$ Instituto Universidade Virtual - Universidade Federal do Ceará (UFC) \\ Fortaleza - CE - Brasil \\ gabiteles2s.as@gmail.com, daniellegonzaga9@gmail.com, \\ robson@virtual.ufc.br
}

\begin{abstract}
The objective is to analyze how the graduates of the discipline Technoteaching use Digital Educational Authorial Materials (DEAM). We proceeded with a Case Study, through spontaneous observation of a hypothetical classroom situation, carried out by two interdisciplinary groups. The research was subdivided into data planning, collection, and analysis. It was observed that a group used the DEAM produced in an instructional manner. In all groups, it was found that the longest period of class was devoted to the dialogued exposition of contents, in which the teacher occupies the center of the teaching action with multidisciplinary classes. However, the productions of DEAM were interdisciplinary.
\end{abstract}

Resumo. $O$ objetivo é analisar como os licenciandos da disciplina Tecnodocência utilizam Materiais Autorais Digitais Educacionais (MADEs). Procedeu-se com Estudo de Caso, por meio de observação espontânea de situação hipotética de aula, realizada por dois grupos interdisciplinares. A pesquisa foi subdividida em planejamento, coleta e análise de dados. Observouse que um grupo utilizou o MADE produzido de maneira instrucionista. Em todos os grupos, verificou-se que o período maior de aula foi destinado à exposição dialogada de conteúdos, em que o professor ocupa o centro da ação docente com aulas multidisciplinares. Entretanto, as produções dos MADEs, foram interdisciplinares.

\section{Introdução}

A história da relação entre a Docência e as Tecnologias Digitais da Informação e Comunicação (TDICs) é iniciada em meados da década de 1950, momento em que os primeiros computadores são comercializados. Nesse contexto, conforme Valente (2001), o computador aparecia como uma máquina capaz de armazenar informações que poderiam ser repassadas aos alunos, em um processo de transmissão. Nesse sentido, observa-se que ao passo em que se tem o boom tecnológico que promove mudanças nos modos de produção e de compartilhamento de informações e conhecimentos, perpetuase, nas práticas cotidianas, um modelo de relação entre a Docência e as TDICs que remonta há cerca de sessenta (60) anos atrás.

Kenski (2007) enfatiza que as TDICs promovem uma reestruturação da consciência e da memória humana, de tal modo que as formas de compreensão e ação 
sobre o mundo são alteradas. Nesse contexto, o trabalho, o lazer, a organização social, o aprender, o ensinar são marcados por outros aspectos. Com novas dinâmicas envolvendo a Docência, faz-se necessário estar "[...] em permanente estado de aprendizagem e de adaptação ao novo" [Kenski 2007, p.60].

Percebe-se que Docência e TDICs demandam o desenvolvimento de mudanças que parece não estar condizente com o cenário contemporânea diante da insistência em uma abordagem pautada na transmissão de saberes absolutos, guiada pela lógica da fragmentação dos saberes. Diante disso, faz-se necessário, conforme Santos (2002), proceder com a ressignificação das práticas curriculares. Nesse contexto, emerge um "novo modelo de saber", guiado não mais pela ideia de aprender o que tradicionalmente era transmitido, mas pela busca do que ainda não havia sido conhecido [Japiassu 2006, p.48].

Conectado a tal fato, Santos (2002) reconhece que esse saber compartimentalizado não é condizente com a sociedade "em rede" presente na contemporaneidade. Nessa seara, a abordagem interdisciplinar aparece como uma possibilidade considerada significativa por diferentes teóricos, como Santos (2002) e Japiassu (2006), ao passo em que se pauta em "[...] experiências intencionais de interação entre as disciplinas com intercâmbios, enriquecimentos mútuos e produção coletiva de conhecimentos" [Santos 2002, p.39].

Compreende-se que diante das possibilidades existentes nas TDICs que, conforme Almeida (2008), ampliam os espaços de interação, potencializam as trocas afetivas e incentivam a produção compartilhada e colaborativa de conhecimentos, faz-se necessário que o docente, ainda em seu processo de formação, se aproprie criticamente destas tecnologias, analisando-as e utilizando-as, para além do modelo preestabelecido.

No construcionismo o aluno assume o centro do processo, produzindo algo de seu interesse pessoal, sendo mobilizado a construir conhecimento. Nessa perspectiva, o docente aparece como mediador, tendo como principal desafio promover desequilíbrios que incentivem o desenvolvimento da descoberta pelo próprio aluno [Papert 2008]. Com base em tal perspectiva, observa-se que a Docência ultrapassa a lógica da transmissão, sendo permeada pela construção, reconhecendo-se o potencial interativo, reflexivo e flexível que a permeia [Tardif e Lessard 2011]. Veiga (2006) ressalta que a Docência é uma construção social, de modo que ela não é ou não deve ser estanque como tem se apresentado historicamente.

Como uma das possibilidades integradoras entre Docência e TDICs, tendo como perspectiva fundamentadora o construcionismo, tem-se a produção de Materiais Autorais Digitais Educacionais (MADEs). Os referidos materiais são desenvolvidos por docentes e/ou discentes com utilização de equipamento digital com "criação, planejamento, execução, reflexão e avaliação realizados pelo próprio aprendiz", reconhecendo-se como aprendiz tanto docentes quanto discentes [Lima e Loureiro 2016, p.630]. Tal proposta de produção de MADEs é utilizada na disciplina Tecnodocência, ofertada pela UFC, em que os licenciandos são desafiados a produzirem tais materiais digitais, devendo integrá-los ao processo de planejamento, execução e avaliação de situações hipotéticas de aula direcionadas a alunos do Ensino Médio de Escola Pública.

Diante disso, considera-se pertinente indagar: Como os licenciandos da disciplina Tecnodocência, ofertada pela Universidade Federal do Ceará (UFC), utilizam Materiais Autorais Digitais Educacionais (MADEs), em situação hipotética de aula? 
O objetivo da pesquisa é, portanto, analisar como os licenciandos da disciplina Tecnodocência, utilizam Materiais Autorais Digitais Educacionais (MADEs) quando pensam no planejamento de uma aula interdisicplinar. Desenvolveu-se um Estudo de Caso, em que foi observado, de maneira espontânea, como dois grupos interdisciplinares utilizaram MADEs em situações hipotéticas de aula, por meio da utilização de diários de campo, relatórios e triangulação metodológica com três focos de análise: centralização da ação docente; perspectiva fundamentadora da utilização das TDICs; e interdisciplinaridade.

\section{Referencial Teórico}

A ideia de se trabalhar com tecnologia no contexto educacional é possível quando se pensa a tecnologia como um produto a ser desenvolvido por alunos e professores [Ricardo 2009]. O grande desafio ao integrar a tecnologia ao contexto educacional é a superação da visão privilegiada que a tecnologia apresenta em relação à concepção social de ciência. $\mathrm{Na}$ formação do professor, é necessário que se possibilite uma alfabetização científica e tecnológica por meio da reorientação dos saberes ensinados e da superação das dificuldades dos professores em abstrair suas experiências.

Ao se trabalhar no contexto das TDICs, esse objetivo é alcançado quando são possibilitados recursos que permitam a exploração, a investigação e a descoberta. No entanto, a mediação do professor nesse processo é fundamental. Por meio do diálogo que estabelece com o aprendiz é que novas ideias podem surgir para que a resolução do problema seja possibilitada. A compreensão sobre esta mediação, no entanto, não surge da simples prática ou da simples compreensão teórica, mas da integração entre ambas. Por isso, compreende-se que o uso da tecnologia digital no contexto da formação do professor de ciências deve englobar o conhecimento da técnica, da tecnologia e de seus diferentes usos, sejam eles científicos ou pedagógicos inseridos no contexto curricular [Almeida 2008].

Em pesquisa desenvolvida por Feitosa (2010), ao observar a dinâmica pedagógica das disciplinas de Estágio Supervisionado no Ensino Fundamental II e Estágio Supervisionado no Ensino Médio ofertadas para licenciandos de Ciências Biológicas do $5^{\circ}$ e $8^{\circ}$ semestres, respectivamente, com o intuito de compreender as contribuições dessas disciplinas para a formação do professor de Biologia percebe-se que as TDICs ainda não são incorporadas ao currículo da formação docente. Os entraves percebidos pelos licenciandos em Ciências Biológicas versam principalmente sobre a repetição dos conteúdos pedagógicos trabalhados nas cinco disciplinas voltadas para a instrumentalização do professor, tornando-as desestimulantes para os licenciandos que as cursam; a intensa teorização do currículo com pouca ênfase na prática docente; e, a falta da apresentação de conteúdos pedagógicos progressivos, o que os desestimula a participar das disciplinas.

Viseu e Ponte (2012), ao estudarem a influência das TDICs no desenvolvimento do conhecimento didático de licenciandos de Matemática e de sua capacidade reflexiva na fase do estágio, percebem que as TDICs possibilitam o desenvolvimento de uma auto avaliação sobre a prática e a ampliação desse conhecimento ao comparar suas ações docentes com a de outros colegas. Apesar de utilizarem apenas e-mail e fórum como ferramentas digitais para discussão e troca de experiências, os resultados foram satisfatórios. $\mathrm{O}$ e-mail auxiliou os sujeitos da pesquisa a desenvolverem sua capacidade reflexiva, permitindo-os pensar antes de escrever, diferentemente do que se faz em uma 
discussão presencial, além de confrontar suas opiniões com as de outros colegas. $\mathrm{O}$ fórum foi considerado mais do que um ponto de encontro entre colegas e orientadores, mas principalmente um ponto de confronto de ideias, o que permitiu discussões fundamentadas em leituras e pautadas nas experiências da prática docente. De acordo com os licenciandos, o repensar durante as discussões virtuais desenvolve a capacidade de questionar.

Os resultados favoráveis alcançados nos cursos de Licenciatura também são percebidos em pesquisas realizadas com docentes universitários de diferentes áreas do conhecimento. Melo (2012), em pesquisa com professores universitários de Língua Inglesa provenientes de instituições públicas e particulares sobre o uso das TDICs na docência percebem que existe uma valorização das tecnologias digitais como ferramentas para tarefas diárias dentro e fora da sala de aula realizadas no contexto presencial ou virtual. Em geral, os docentes utilizam as ferramentas computacionais de formas variadas, de acordo com seus objetivos para facilitar seu trabalho. As atividades buscam promover a prática das habilidades de leitura e conversação e discussões em chats sobre conteúdos e artigos abordados no momento das aulas presenciais.

Para a superação da fragmentação dos saberes na formação docente se fazem necessário o pensar e o fazer integrados a partir da compreensão teórica e prática dos diferentes saberes ressaltados: conteúdo específico, pedagógicos (currículo e ensinoaprendizagem) e TDICs [Lima 2014].

\section{Metodologia}

O desenvolvimento da presente pesquisa teve como base metodológica o Estudo de Caso, modalidade em que o pesquisador se debruça, de maneira empírica, sobre fenômenos contemporâneos sob os quais não se tem controle. Nessa modalidade, não há clareza com relação aos limites existentes entre o fenômeno e o contexto [Yin 2010]. As questões norteadoras do Estudo de Caso são do tipo como e/ou por que, direcionando-se para uma pesquisa que foca na descrição e/ou na análise do que está sendo pesquisado.

Conforme Gil (2010), o Estudo de Caso tem como principais objetivos investigar fenômenos que ocorrem no contexto real; preservar a unidade relativa ao objeto em estudo; descrever o contexto que compõe o fenômeno investigado; criar hipóteses e/ou teorias; descrever e analisar as causas que permeiam o fenômeno pesquisado considerando a sua complexidade.

Para a coleta de dados foram observadas situações hipotéticas de aula desenvolvidas por dois (02) grupos interdisciplinares, organizados pelos docentes da disciplina Tecnodocência. Ressalta-se que os grupos em questão, estavam formados, no total, por onze (11) discentes, sendo que dois (02) destes estavam vinculados à curso de Bacharelado, de maneira que os seus dados não compuseram a análise realizada nesta pesquisa. Desse modo, dos nove (09) licenciandos que formaram a unidade de análise da pesquisa, observou-se que 55,56\% se encontram na faixa etária de 21 a 25 anos; $11,11 \%$ estão na faixa de 26 a 30 anos; $11,11 \%$ têm entre 31 e 35 anos; $11,11 \%$ fazem parte da faixa etária de 36 a 40 anos; e 11,11\% inserem-se no grupo acima de 40 anos.

Considerando-se que a abordagem interdisciplinar faz parte da proposta trabalhada na disciplina Tecnodocência, verificou-se uma variedade de cursos de licenciatura presentes nos grupos estudados, a saber: Letras/Inglês; Química; Matemática; Ciências Biológicas; História; Pedagogia; Letras/Português/Francês e Física. Destaca-se 
que cada curso contou com um representante. Somente o curso de História contou com dois participantes dentro do contexto pesquisado. Acerca do semestre cursado pelos sujeitos participantes da pesquisa, obteve-se que $33,33 \%$ estavam matriculados entre o $1^{\circ}$ e o $3^{\circ}$ semestre; e $66,67 \%$ cursavam a partir do $7^{\circ}$ semestre. Tal cenário evidencia que a maioria dos licenciandos que compuseram a pesquisa encontram-se nos últimos semestres o que pode evidenciar uma base teórica constituída em relação à Docência e os aspectos que a formam.

Ainda sobre o contexto em que a pesquisa foi desenvolvida, salienta-se que a disciplina Tecnodocência é de caráter optativo, estando inserida no Instituto Universidade Virtual (IUVI), destinando-se à formação de licenciandos. O foco de abordagem da disciplina é o processo de integração entre Docência e TDICs, tendo-se o desenvolvimento de trabalho teórico e prático, pautado na Teoria da Aprendizagem Significativa, na Filosofia da Diferença, na Interdisciplinaridade, na Teoria de Fluxo e no Construcionismo.

Subdividiu-se a pesquisa em três etapas: planejamento, coleta e análise de dados. A etapa relativa ao planejamento foi iniciada com a produção dos protocolos de coleta de dados, dos instrumentos de coleta e de análise, bem como da política de armazenamento. Conforme Yin (2010) o protocolo se constitui em um elemento necessário para o desenvolvimento de Estudos de Caso, ao passo em que ele orienta o pesquisador em seu processo de coletar dados.

A segunda etapa, relativa à coleta de dados, ocorreu por meio de observação espontânea das situações hipotéticas de aulas desenvolvidas pelos dois grupos interdisciplinares com os alunos do Ensino Médio com registro em diário de campo. De acordo com Gil (2010), no referido tipo de observação, o pesquisador debruça-se sobre o fenômeno investigado sem realizar interferências. Considera-se pertinente salientar que as situações hipotéticas de aula supracitadas correspondem a uma das atividades desenvolvidas na disciplina Tecnodocência, em que os grupos interdisciplinares, previamente organizados, executam os planos de aula construídos ao longo do semestre. Nesse momento específico, os grupos interdisciplinares simulam a realização de uma aula, tendo como público os alunos do Ensino Médio de escola pública parceira da UFC. Para isso, é disponibilizado o tempo de cinquenta (50) minutos para que cada grupo realize a aula, utilizando o MADE produzido em momento anterior e tendo como base a Interdisciplinaridade e o Construcionismo.

Para a análise dos dados, os elementos observados nos dois grupos interdisciplinares foram triangulados a partir de três focos de análise [Yin 2010]. A centralização da ação docente se constituiu no primeiro foco, de modo que foi verificado se os licenciandos consideram o professor, o aluno, o conteúdo ou outro aspecto como centro do processo. O segundo foco consistiu na utilização das TDICs, identificando-se se, quais e como estas foram utilizadas. O terceiro foco de análise foi a Interdisciplinaridade, sendo observado com base em qual modelo epistemológico de construção do conhecimento os licenciandos utilizaram o MADE na situação hipotética de aula desenvolvida.

\section{Resultados e Discussão}

Diante da realização da pesquisa, foram obtidos resultados considerados mobilizadores de discussões relativas ao estudo da temática em discussão: Integração entre Docência e 
TDICs com a produção de MADEs por licenciandos. Salienta-se que os resultados serão apresentados tendo como base os dois grupos interdisciplinares que compuseram a pesquisa, sendo desenvolvida a triangulação metodológica.

Desse modo, os resultados obtidos a partir dos dados coletados em cada grupo serão descritos e analisados, sendo considerados o referencial teórico e os focos de análise sob os quais a pesquisa se baseia.

Com o intuito de facilitar a comunicação e de manter o sigilo considerado necessário para a garantia do aspecto da ética na pesquisa, os grupos interdisciplinares serão identificados a partir da seguinte nomenclatura: G1 e G2.

\subsection{Resultados do G1}

O G1 estava composto por quatro (04) licenciandos das seguintes áreas: Letras/Inglês; Química; Matemática e Física. A situação hipotética de aula desenvolvida pelo grupo ocorreu sob a temática Computadores com a abordagem dos conteúdos Sistema Binário; Oxirredução; Capacitadores; Linguagem/Vocabulário da Língua Inglesa.

O MADE utilizado pelo grupo na simulação de aula em questão consistia em um blog que o grupo havia produzido em momento anterior. $\mathrm{Na}$ área destinada ao conteúdo de Inglês, constava um link de um Quiz, disponível na internet, que deveria ser respondido pelos alunos da escola pública.

O G1 desenvolveu a aula no tempo de uma (01) hora, tendo sido destinado cinquenta e um (51) minutos à exposição de conteúdos e somente nove (09) minutos para a utilização dos MADEs pelos alunos. Assim, observa-se que o grupo centralizou a ação docente no professor (papel exercido pelos licenciandos) e/ou nas TDICs, enfatizando-se que o blog criado pelo grupo auxiliou os licenciandos no processo de exposição de conteúdos, sendo utilizados como slides.

Com relação à centralização da ação docente no professor, Sibilia $(2012$, p.53) ressalta que o modelo de Docência imperante há séculos evidencia um estado de espera por seu "atestado de óbito", não sendo mais condizente com o contexto que a cerca e com os atores que a envolvem. Nesse sentido, o papel historicamente exercido pelo professor, como transmissor de conhecimentos, precisa ser refletido e repensado, principalmente em seu processo de formação docente, de maneira que ele seja mobilizado a se apropriar criticamente, na teoria e na prática, do contexto de boom tecnológico evidenciado e dos aspectos que o marcam no âmbito educacional [Kenski 2007].

No que se refere ao segundo foco de análise da pesquisa, em que foi observado se, como e sob quais bases os licenciandos utilizaram as TDICs, foi possível perceber que o G1 utilizou tais tecnologias digitais, por meio do blog criado e do Quiz utilizado. Sobre o modo como estas tecnologias foram utilizadas, destaca-se que o grupo fez uso do blog durante toda a aula para apresentar os conteúdos relativos à cada área do conhecimento $\mathrm{e}$ do Quiz nos últimos minutos da aula, constituindo-se na única atividade desenvolvida pelos alunos da escola pública.

Ressalta-se que nas duas situações o MADE foi utilizado de maneira instrucionista, em que as tecnologias digitais assumem o centro do processo, tendo a função de repassar instruções preestabelecidas [Valente 2001]. Nessa perspectiva, o aluno prossegue como expectador que recebe e executa os comandos dados pelo docente e/ou pela máquina, seguindo a lógica do condicionamento operante, inexistindo o produto 
construído pelo aprendiz/aluno [Almeida 2008].

Quanto à Interdisciplinaridade, foi possível constatar que tanto a situação hipotética de aula desenvolvida pelo G1 quanto o MADE utilizado na ocasião estavam conectados à abordagem multidisciplinar, que se configura, conforme Santos (2002) como uma tentativa de articulação dos saberes. Em tal abordagem, verifica-se o desenvolvimento de um trabalho que demanda a participação de disciplinas diferentes, mas inexiste integração entre estas, apresentando apenas uma justaposição.

Santos (2002) enfatiza que na multidisciplinaridade não há a contextualização, de maneira que os conteúdos abordados se apresentam de maneira não significativa aos sujeitos, pois estão desconectados de suas realidades e vivências.

Considera-se pertinente salientar que a proposta da atividade era que os licenciandos, organizados em grupos heterogêneos desenvolvessem uma aula pautada, dentre outros aspectos, na Interdisciplinaridade. Nesse sentido, verifica-se a dificuldade vivenciada pelo G1 em praticar tal abordagem, diante de uma histórica associação entre a Docência e a fragmentação dos saberes.

\subsection{Resultados do G2}

O G2 foi organizado contando com a participação de três (03) componentes vinculados às seguintes áreas do saber: Ciências Biológicas; História e Música. A aula desenvolvida pelo referido grupo ocorreu com o tema Cinema, tendo como subtema específico o filme "O Físico". A partir disso, o G1 abordou os conteúdos Epidemiologia; Idade Média; e Análise Musical.

Para compor a aula, o grupo criou um canal no YouTube, em que os alunos deveriam enviar as suas produções. Salienta-se que o G2 já havia planejado e desenvolvido o MADE em questão em aula anterior, tendo a tarefa de utilizá-lo na aula com os alunos da escola pública.

Desse modo, o grupo utilizou trinta e cinco (35) minutos, dentro de uma aula realizada em sessenta (60) minutos, para a exposição de conteúdos, em que cada licenciando abordou o conteúdo relativo à sua área específica tendo como norte a temática do filme "O Físico". Ressalta-se que nesse momento foram apresentados trechos do filme e, a partir deles, foi desenvolvida a exposição dialogada dos conteúdos.

Verifica-se, assim, como no caso do G1, a correlação estabelecida pelos licenciandos entre a Docência e a exposição de conteúdos preestabelecidos pelo professor, em um modelo vigente e perpetuado há séculos que nega a concepção do fazer docente como construção social [Veiga 2006] e como trabalho de um com o outro, e não de um para o outro [Tardif e Lessard 2011].

Dessa forma, reafirma-se no contexto da presente pesquisa, a necessidade de um repensar, teórico e prático, da Docência e, por conseguinte, do processo de formação docente que precisa ser mobilizador do desenvolvimento de outras práticas, de outras formas de fazer Docência.

Lima (2014) ressalta que a formação inicial dos licenciandos tem se pautado em aspectos predominantemente teóricos e vinculados somente ao ensino, e não à aprendizagem. Nessa mesma perspectiva, Lima e Loureiro (2016) enfatizam que a formação docente é orientada por uma abordagem fragmentada, que não conecta e 
equilibra as disciplinas teóricas e práticas e que está desvinculada do contexto dos alunos, inclusive no que se refere ao aspecto tecnológico.

Com relação à utilização das TDICs pelo G2 na situação hipotética de aula, observou-se que o grupo fez uso de slides e de vídeo nos momentos de exposição de conteúdos, pautando-se na perspectiva instrucionista. Entretanto, no momento de utilização do MADE, o grupo teve como base a perspectiva construcionista, de modo que os alunos da escola pública, organizados em equipes, produziram paródias relacionadas aos conteúdos trabalhados, utilizando o software Audacity, e as disponibilizaram no canal criado pelo G2 no YouTube.

No construcionismo, conforme Valente (2001), o aluno/usuário ensina o computador, produzindo algo novo que é de seu interesse, de maneira que o centro da ação docente nessa perspectiva é o aluno, e não o professor e/ou as TDICs. Nesse processo, o professor aparece como mediador, oferecendo as condições necessárias para que os alunos desenvolvam os seus produtos em um processo de descrição, execução, reflexão e depuração.

Entretanto, ressalta-se que a atividade de produção das paródias não foi concluída pelos alunos, destacando-se que a maior parte da aula foi destinada à exposição de conteúdos, restando pouco tempo para o processo de produção. Além disso, o G2 experenciou dificuldades na utilização do software escolhido o que pode evidenciar o desconhecimento do software em questão.

Sobre o terceiro foco de análise da pesquisa, verificou-se que, assim como o G1, esse grupo desenvolveu uma aula multidisciplinar, em que cada licenciando abordou o conteúdo relativo à sua área, sem estabelecer conexões, em um processo de justaposição.

Porém, ao utilizar o MADE e propor a sua produção por parte dos alunos, percebeu-se a presença da abordagem interdisciplinar, em que se tem "a interação entre as disciplinas", de maneira intencional, a partir de um tema norteador [Santos 2002, p.39]. Tal fato foi percebido quando o G2 propôs que os alunos, organizados em equipes, produzissem paródias em que os conteúdos abordados fossem conectados a partir de temáticas relacionadas às suas preferências.

Considera-se, assim, a partir da experiência do G2, que as construções, teóricas e práticas, desenvolvidas na disciplina Tecnodocência, podem ter mobilizado os licenciandos a perceberem outras possibilidades de Docência, mesmo que ainda tenham centralizado a ação docente no professor e utilizado a abordagem multidisciplinar no maior período da aula.

\section{Considerações Finais}

Diante do desenvolvimento da presente pesquisa que teve como objetivo analisar como os licenciandos da disciplina Tecnodocência, ofertada pela UFC, utilizam Materiais Autorais Digitais Educacionais (MADEs), em situação hipotética de aula, pôde-se visualizar aspectos considerados significativos para a análise do processo de integração entre Docência e TDICs no âmbito da formação docente.

Com relação ao primeiro foco de análise, verificou-se que os licenciandos, mesmo diante de uma proposta interdisciplinar e construcionista, evidenciaram dificuldades em perceberem a Docência sob outros moldes, que não a transmissão de conhecimentos preestabelecidos, em que o professor aparece como centro da ação docente. 
Ressalta-se que tal aspecto foi percebido nos dois grupos analisados que, ao desenvolverem as situações hipotéticas de aula, utilizaram a maior parte do tempo para expor os conteúdos relativos às suas áreas de estudo, restando pouco tempo para a produção dos alunos, bem como para a apresentação dos seus produtos.

No que se refere à utilização das TDICs, percebeu-se que todos os grupos, ao ocuparem-se com a exposição dos conteúdos, utilizaram estas tecnologias de maneira instrucionista, por meio da apresentação de slides, vídeos e/ou blogs. No momento em que a proposta era a utilização dos MADEs, observou-se que somente um dos grupos permaneceu baseando a sua ação na perspectiva instrucionista. O outro optou por uma ação construcionista, pautada na construção do conhecimento pelo aluno. Porém, diante do tempo gasto inicialmente com a exposição de conteúdos foram percebidas dificuldades para que os alunos desenvolvessem e apresentassem os seus produtos.

Sobre o terceiro foco de análise, foi possível verificar que os dois grupos realizaram aulas multidisciplinares. Entretanto, propuseram que os alunos utilizassem os MADEs de maneira interdisciplinar, sendo obtidos produtos que evidenciavam tal abordagem, em que as disciplinas são integradas com base em uma temática comum, observando-se uma possível conexão entre a perspectiva construcionista e a interdisciplinaridade.

Nesse sentido, considera-se pertinente o desenvolvimento de uma formação docente que mobilize os licenciandos a integrarem Docência e TDICs, conhecendo as duas perspectivas que norteiam tal relação, tanto em âmbito teórico quanto em âmbito prático. O acesso e a utilização de outros modos de fazer Docência aparecem como elementos necessários para que esses sujeitos sejam munidos de um vasto arcabouço de possibilidades, desconstruindo a concepção que associa Docência somente a um determinado modelo historicamente estabelecido.

Salienta-se a pretensão em dar continuidade a pesquisa, diante da oferta da disciplina Tecnodocência em semestres subsequentes e aprofundamento da investigação considerando-se outros focos de análise.

\section{Referências}

Almeida, M. E. B. de. (2008) "Tecnologias na Educação: dos caminhos trilhados aos atuais desafios". Bolema, Rio Claro, v.21, n.29, p.99-129.

Feitosa, R. A. (2010) "Formação de Professores de Ciências Biológicas na UFC: um estudo de caso a partir do Estágio Supervisionado". Dissertação (Programa de PósGraduação em Educação Brasileira) - Faculdade de Educação, Universidade Federal do Ceará, Fortaleza.

Gil, A. C. (2010) “Como Elaborar Projetos de Pesquisa”. São Paulo: Atlas.

Japiassu, H. "O Sonho Transdisciplinar e as Razões da Filosofia”. Rio de Janeiro: Imago, 2006.

Kenski, V. M. (2007) "Educação e Tecnologias: O novo ritmo da informação". Campinas: Papirus.

Lima, L. de. (2014) "Integração das Tecnologias e Currículo: a aprendizagem significativa de licenciandos de ciências na apropriação e articulação entre saberes científicos, pedagógicos e das TDICs”. 366f. Tese (Programa de Pós-graduação em 
Educação Brasileira) - Faculdade de Educação, Universidade Estadual do Ceará, Fortaleza.

Lima, L. de e Loureiro, R. C. (2016) "Integração entre Docência e Tecnologia Digital: o desenvolvimento de Materiais Autorais Digitais Educacionais em contexto interdisciplinar". Revista Tecnologias na Educação, Fortaleza, v.17, n.8, p.1-11.

Melo, G. C. V. de. (2012) "O uso das TIC no trabalho de professores universitários de língua inglesa”. RBLA, Belo Horizonte, v. 12, n. 1, p. 93-118.

Papert, S. (2008) “A Máquina das Crianças: repensando a escola na era da informática”. Porto Alegre: Artes Médicas.

Ricardo, E. C. (2007) "Educação CTSA: Obstáculos e possibilidades para sua implementação no contexto escolar". Ciência \& Ensino, vol. 1, número especial.

Santos, E. O. dos. (2002) "O currículo e o digital: Educação presencial e a distância". 75 f. Dissertação (Mestrado Acadêmico em Educação) - Faculdade de Educação, Universidade Federal da Bahia, Salvador.

Sibilia, P. (2012) "Redes ou paredes: a escola em tempos de dispersão". Rio de Janeiro: Contraponto.

Tardif, M. e Lessard, C. (2011) "O trabalho docente: elementos para uma teoria da docência como profissão de interações humanas". Petrópolis: Editora Vozes.

Valente, J. A. (2001) “A Informática na Educação: Como, Para que e Por que”. Revista de Ensino de Bioquímica, São Paulo, s/v, n.1.

Veiga, I. P. A. (2006) "Docência universitária na educação superior". In Ristoff, D; Sevegnani, P. (org). Docência na Educação Superior. Brasília: Instituto Nacional de Estudos e Pesquisas Educacionais Anísio Teixeira.

Viseu, F. e Ponte, J. P. da. (2012) “A Formação do Professor de Matemática, apoiada pelas TIC, no seu Estágio Pedagógico”. Bolema, Rio Claro (SP), v. 26, n. 42A, p. 329-357.

Yin, R. K. (2010) "Estudo de caso: planejamento e métodos”. Porto Alegre: Bookman. 